\title{
TRANSIÇÃO PARADIGMÁTICA DO ENSINO SUPERIOR ANTE A ESTRATÉEIA 12.7 DO PLANO NACIONAL DE EDUCAÇÃO \\ DOI: dx.doi.org/10.18616/inser01
}

Simone Loureiro Brum Imperatore ${ }^{1}$

\section{INTRODUÇÃO}

Da gênese da extensão universitária do Brasil à contemporaneidade, o fazer extensionista configura-se como a interlocução da universidade com a sociedade. Sua construção histórica, orientada pela concepção acadêmica, regulação do Ministério da Educação, atuação do movimento estudantil e Fóruns de Pró-Reitores de Extensão, apresenta mais contradições do que convergências na sua delimitação conceitual enquanto elo indissociável (e impreciso) entre ensino e pesquisa, instrumento de diálogo e compromisso social da universidade com a sociedade (FARIA, 2001). Extensão, ao mesmo tempo autoritária (FREIRE, 2006b) e redentora, dissemina conhecimentos (para quem não sabe), presta serviços (assistencialismo), intervém na sociedade e "promove" a cultura. Extensão compreendida como caça-níqueis (DEMO, 2001) e promotora da troca entre os saberes acadêmico e popular (TAVARES, 2001). Extensão legitimada por seu caráter funcionalista e processual, distante da concepção de uma extensão crítica e, reconhecidamente, com dimensão acadêmica.

Extensão ressignificada pelo Plano Nacional de Educação 20142024 (Lei n 13.005/2014), define, dentre suas estratégias, a integralização de, no mínimo, dez por cento do total de créditos curriculares exigidos

${ }^{1}$ Doutora em Diversidade Cultural e Inclusão Social. Atualmente, é Diretora de Assuntos Comunitários da Universidade Luterana do Brasil. E-mail: simone@imperatore.com.br 
nos cursos de graduação, por meio de programas e projetos de extensão em áreas de pertinência social (BRASIL, 2014a). Nesse sentido, o presente capítulo resgata, sinteticamente, a gênese, os conceitos e as contradições da extensão universitária, bem como realça sua função acadêmica, sob uma concepção crítica e emancipatória integrada ao currículo. Reflete sobre o Plano Nacional de Educação, com ênfase à estratégia 12.7, apontando a transição paradigmática vigente do ensino superior. De cunho bibliográfico, descritivo e prospectivo, objetiva dimensionar trajetórias possíveis, entraves e dificuldades da intitulada curricularização.

\section{EXTENSÃO UNIVERSITÁRIA: GÊNESE, CONCEITOS E CONTRADIÇÕES}

A semântica do termo extensão, por si só, denuncia incongruências. Estender o perímetro da universidade? Estender o conhecimento? Constituir-se em ponte entre o saber "legítimo" e a sociedade iletrada? "Socializar" a cultura? "Atender" à comunidade? Tornar a universidade socialmente relevante? Na proposição de um brainstorming sobre extensão universitária, invariavelmente, seriam elencadas as seguintes ações/ conceitos: cursos; eventos esportivos, científicos e culturais; extensão rural; consultorias/assessorias (prestação de serviços diversos); atendimentos multiprofissionais, programas/projetos, extensão tecnológica, estágios; responsabilidade social; assuntos comunitários; políticas públicas; relação dialógica universidade-sociedade; formação cidadã. Essa polissemia deriva da gênese da extensão, das contradições de seu trajeto histórico, da crise identitária da universidade.

De sua gênese, porque resultante de um modelo híbrido e exógeno que conjuga os padrões europeus (cursos) e norte-americanos (conferências e prestação de serviços), quer sob a censura e a vigília do Estado, quer a serviço de sua legitimação e ou instrumento de promoção da polí- 
tica desenvolvimentista. De outra parte, sua história evidencia a omissão, a indiferença e os paradoxos, ora do marco regulatório do Ministério da Educação, ora da retórica versus práxis das universidades, ora do clamor dos movimentos estudantis e sociais. São muitas as versões de uma mesma trajetória que descendem da crise identitária de um modelo de universidade elitista e produtiva, conformada à Igreja, ao Mercado e/ou ao Governo, quase sempre alheia à sociedade em sua breve cronologia no Brasil. Em quaisquer dos entendimentos, visível a dicotomia de uma extensão marginal e autoritária. Marginal, porque é subalterna ao ensino e à pesquisa e periférica ao currículo. Autoritária na "intervenção" extramuros, na difusão do saber hegemônico, na ação assistencialista.

Cabe-nos refletir acerca de uma fundamentação teórica que desnude as contradições herdadas e elucide a ação extensionista. Para isso, valho-me da política nacional de extensão que enuncia: “[...] processo acadêmico definido e efetivado em função das demandas sociais, políticas, econômicas e culturais da sociedade e da proposta pedagógica dos cursos, coerente com as políticas públicas e indispensável à formação cidadã." (FORPROEX, 2012). A primeira qualificação, extensão enquanto processo acadêmico, depõe, em grande medida, as práticas (atuais) dissociadas do currículo e alheias à pesquisa, conforme assevera Jezine (2004, n.p.):

A abordagem teórica que defende a extensão como função acadêmica da universidade objetiva integrar ensino-pesquisa, e a que incorpora a extensão universitária às práticas de ensino e pesquisa parte da crítica da extensão voltada à prestação de serviços em uma perspectiva assistencialista, qual seja a extensão voltada ao atendimento das necessidades sociais das camadas populares.

Ao se aprofundar sobre a reflexão conceitual, a referência “[...] definido e efetivado em função das demandas sociais, políticas, econômicas 
e culturais da sociedade [...]" (FORPROEX, 2012), afirma-se a reconexão universidade-sociedade em uma perspectiva dialógica, corresponsável e solidária. A correlação à "proposta pedagógica dos cursos" e à "formação cidadã”, por sua vez, ratifica o princípio educativo da extensão, sua dimensão acadêmica, cogeradora de conhecimentos, competências, habilidades e atitudes, a partir da vinculação com a realidade social, o que Gramsci (1989, p. 130) refere em proporcionar “[...] um novo pensar e fazer, capaz de desenvolver uma concepção histórica de sujeito e sociedade”. Por fim, a aludida coerência com as políticas públicas nos remete a um projeto sistêmico de articulação entre Estado, universidade e sociedade, a fim de contribuir para o desenvolvimento econômico e social de seu entorno e para a realimentação do conhecimento.

Do exposto, depreende-se uma extensão alinhada à proposta do "modo de ser universidade", institucionalizada e, objetivamente, manifesta nos projetos pedagógicos dos cursos (linhas de extensão e pesquisa), alicerçada na quadríade extensão, pesquisa, ensino e gestão. Destaco que, mais do que um jogo semântico, a ordem (re)estabelecida remete ao papel da extensão como orientação da pesquisa, que retroalimenta o ensino e fundamenta a gestão acadêmica. Não a ordem inversa, que se impõe no modelo atual, a qual subordina ensino e pesquisa aos ditames da "educação-negócio" e marginaliza a extensão, conformando-a a práticas assistencialistas e à sua mercantilização, resumindo-a em um balcão de negócios, com a objetiva finalidade de captação de recursos extraorçamentários, conforme destaca Botomé (1996).

\section{EXTENSÃO UNIVERSITÁRIA ENQUANTO FUNÇÃO ACADÊMICA}

Ato contínuo ao alinhamento conceitual, o fazer extensão nos coobriga a repensá-la enquanto função acadêmica, depondo seu caráter 
eventual e assistemático, opondo-se ao conceito de "universidade cidadã", de ações solidárias com públicos vulneráveis (ou abrandamento de sua consciência) realizadas por professores com menor titulação, com sobras de carga horária, parcos recursos materiais, inexpressiva participação discente e escassa produção científica. Botomé (1996, p. 58) destaca que “[...] desde a sua gênese, a extensão universitária parece ser uma 'compensação' pelo ensino alienado e pela pesquisa descomprometida com a realidade social". Nesse sentido, Sousa (2010, p. 120) complementa:

A Extensão Universitária vai surgir posteriormente e também como uma resposta às demandas externas da Universidade. Inicialmente surgiu a Universidade no Brasil, para depois esta incorporar a Extensão como mais uma de suas funções. As Universidades foram criadas sem a preocupação de efetivar esta função. Só mais tarde é que conseguimos reconhecer esta prática entre as demais. Torna-se significativo, portanto, afirmarmos que não se trata de uma função inerente à Universidade, mas é, de fato, mais uma função assumida pela academia, como tentativa de resposta às indagações sobre sua presença na sociedade.

Cabe destacar que a função do ensino, quer seja a transmissão ou a reprodução do conhecimento científico, representa a base das instituições de ensino superior, afirmação que é ratificada pela natureza das 2.391 instituições de ensino superior brasileiras, das quais 195 são de natureza universitária e 2.196 não universitárias, sendo 140 centros universitários, 2.016 faculdades, 40 institutos federais de educação e centros federais de educação tecnológica (BRASIL, 2013). No tocante à pesquisa, surge por pressão da sociedade industrial emergente, ávida por conhecimentos científicos e tecnológicos, a inovação, que, desde a sua origem, como produtora de conhecimento, assume um status destacado na academia, dada a sua potencialidade (e competência) em transformar tecnologia em produto empresarial e, portanto, sua facilidade em alavancar recursos/investimentos. 
Estabelece-se a dicotomia educação-trabalho na universidade, conforme assevera Santos (2013, p. 383):

Assim, a educação, que fora inicialmente transmissão da alta cultura, formação do caráter, modo de aculturação e de socialização adequado ao desempenho da direção da sociedade, passou a ser, também, educação para o trabalho, ensino de conhecimentos utilitários, de aptidões técnicas especializadas, capazes de responder aos desafios do desenvolvimento tecnológico no espaço da produção.

E eis que a universidade "assume" a extensão sob diversas concepções, as quais Silva (2001) resume: a) concepção tradicional ou funcionalista: a universidade é vista como complemento do Estado, executora de políticas educacionais e, por conseguinte, a extensão configura-se no atendimento às carências imediatas da população carente, sob uma perspectiva apolítica e assistencialista; b) concepção processual: assume-se a extensão como compromisso social da universidade, a consciência social da universidade, propondo-se a articulação entre ensino, pesquisa e extensão; c) concepção crítica: sob essa concepção, a extensão está intrinsicamente ligada ao ensino e à pesquisa, passando a integrar-se ao currículo, transformando-se em ensino e pesquisa comprometidos com a realidade.

Ao defender a concepção crítica de extensão, enquanto processo formativo integrado ao currículo, emancipatório e cogerador de conhecimentos, reconheço, como sugere Faria (2001), três núcleos conceituais que a constituem, diretamente relacionados à sua história: conceitos alinhados às áreas de atuação da extensão, conceitos articulados ao ensino e à pesquisa, conceitos identificados com a interação universidade-sociedade. Tais núcleos evidenciam, sinteticamente, a trajetória (e contradições) da extensão: disseminação do conhecimento, das artes e da cultura, passando pela interação ensino-pesquisa e culminando com a promoção da integração à 
sociedade, por meio do conhecimento crítico, reflexivo e comprometido com a realidade social.

Como ponto de partida para a implementação de uma "extensão crítica", elenco a territorialização da universidade, a deposição dos muros e da segmentação "comunidade interna" e "comunidade externa", e a cartografia de indicadores sociais, econômicos, culturais, ambientais. À leitura territorial conjuga-se a revisão dos objetivos/diretrizes institucionais; a sistematização de políticas, fluxos, processos e indicadores; a rediscussão da proposta pedagógica dos cursos e a definição e linhas de extensão e pesquisa; o mapeamento das metodologias aplicadas; a "contabilização" curricular das diferentes funções - ensino-pesquisa-extensão -, na perspectiva quantitativa e qualitativa; a reestruturação dos planos de aprendizagem (englobando extensão-pesquisa-ensino); o realinhamento da estrutura de gestão. No contexto de uma extensão crítica, portanto, esta abandona o curso marginal ao currículo, passando a norteá-lo e fundindo-se à proposta de formação dos cursos de graduação.

\section{O PLANO NACIONAL DE EDUCAÇÃO (PNE) E A TRANSIÇÃO PARADIGMÁTICA DO ENSINO SUPERIOR}

A estratégia 12.7 do Plano Nacional de Educação - PNE (BRASIL, 2014a, n.p.) desvela uma transição paradigmática no ensino superior brasileiro: “[...] assegurar, no mínimo, 10\% (dez por cento) do total de créditos curriculares exigidos para a graduação em programas e projetos de extensão universitária, orientando sua ação, prioritariamente, para áreas de grande pertinência social". Quase desapercebida dentre outras tantas estratégias para elevação da taxa bruta de matrícula no ensino superior, prenuncia a potencialidade de rompimento com o modelo de universidade vigente no País, a partir da reconexão social/territorial das instituições, da ressignificação do ensino superior e da integração da extensão ao currí- 
culo, orientada por programas e projetos. Entende-se por programas “[...] o conjunto articulado de projetos e outras ações extensionistas de caráter multidisciplinar e integrado a atividades de pesquisa e de ensino, executado a médio e a longo prazos por alunos, orientados por um ou mais docentes da instituição." (BRASIL, 2014a).

Em linhas gerais, o Plano Nacional de Educação alicerça os documentos institucionais (PPI, PDI, Regimentos, Regulamentos, Portarias, entre outros) e, associado às Diretrizes Curriculares Nacionais (DCNs), diretrizes e legislações específicas dos cursos, políticas públicas aderentes aos cursos e Política Nacional de Extensão, orienta a institucionalização do fazer extensionista e sua sistematização em programas e projetos que atendam, reciprocamente, a objetivos/demandas comunitários/as e a objetivos de formação acadêmica.

Nos Projetos Pedagógicos dos Cursos, são delimitadas as linhas de extensão e pesquisa que orientarão o escopo de programas de extensão, aos quais estarão vinculados os projetos (conjunto de ações estruturadas, com periodicidade e objetivos definidos), cujas ações serão efetivadas por meio de atividades interdisciplinares (diagnósticos/avaliações/levantamentos, atividades culturais e esportivas, prestação de serviços/assessoria/consultoria, extensão tecnológica, cursos, eventos, entre outros). Tais atividades poderão estar vinculadas a disciplinas específicas dos cursos que contemplem atividades extensionistas em seus planos de ensino e processos avaliativos e/ou poderão ser desenvolvidas em programas/projetos transversais com creditação curricular regulamentada por meio de unidades curriculares.

No caso de integração da extensão às disciplinas, destaco a necessária orquestração entre disciplinas do curso (e/ou de cursos diferentes no caso de disciplinas comuns) na execução de um cronograma de ações planejadas, sob o escopo de um projeto específico e coordenado por um ou mais docentes, validado previamente pelo Núcleo Docente Estruturante do Curso (NDE), à luz das diretrizes curriculares estabelecidas e do respectivo perfil de formação do egresso. Nesse caso, teremos na matriz curricular 
uma tipificação de disciplinas (teórica formação geral, teórica formação específica, práticas/profissionalizantes, extensão/iniciação científica, por exemplo), com vistas a evidenciar a estrutura qualitativa e quantitativa do percurso curricular. Ainda, unidades curriculares, voltadas a componentes obrigatórios e transversais, por exemplo, poderão ser pensadas sob a estrutura de projetos extensionistas (educação ambiental, direitos humanos, cidadania, relações étnico-raciais, diversidade cultural, inclusão, outros), tendo normatizada a forma de integralização curricular. Em ambos os casos, penso uma matriz de núcleos geral e específico de formação, acrescido um núcleo flexível que mapeie potencialidades de integração da extensão (observados os $10 \%$ exigidos).

Um modelo híbrido também é factível, a partir da conjugação das duas alternativas anteriores: projetos integrados ao plano de ensino de disciplinas específicas ou projetos sem vinculação a disciplinas (no formato que hoje são concebidos). De qualquer forma, urge a releitura do currículo proposto e a reflexão acerca do que Menéndez et al. (2013) definem como uma "otra forma de enseñar y de aprender". Nessa conjuntura, metodologias aplicadas à educação a distância constituem fontes de inspiração no pensar a aplicabilidade da pedagogia por projetos, por meio da conexão, interação e articulação de múltiplos saberes a partir do contexto, da realidade, da autonomia e da experienciação. Ainda, um capítulo à parte deve ser pensado para os cursos superiores tecnológicos, dadas as suas especificidades, mas penso que a integração da extensão dar-se-á a partir dos componentes curriculares obrigatórios anteriormente elencados e da extensão tecnológica aplicada à inovação social (inclusão social, geração de trabalho e de renda, qualidade de vida).

Em quaisquer das alternativas, cabe destacar a necessidade de uma definição institucional de educação. O curso da ruptura epistemológica proposta se estrutura, operacionalmente, em um sistema de registro, monitoramento, controle e avaliação integrado, assim como em uma nova estrutura de governança e de gestão, visto que a indissociabilidade exten- 
são-pesquisa-ensino tenciona a departamentalização existente e tem como pilares uma formação docente contínua, lastreada pela compreensão do conhecimento como fenômeno multidimensional. "O conhecimento é, portanto, um fenômeno multidimensional, de maneira inseparável, simultaneamente físico, biológico, cerebral, mental, psicológico, cultural e social." (MORIN, 2012, p. 18).

A legitimação da extensão como função acadêmica prescinde, ainda, da universalização da participação discente e da conciliação de objetivos acadêmicos e das demandas/objetivos comunitárias/os. A Figura 1 sintetiza o que convencionei intitular cartografia da implementação da estratégia 12.7 e é replicável a diferentes trajetórias, tendo como condição, sine qua non, a deposição da fragmentação e da especialização do conhecimento (e das relações de poder intrínsecas), conforme destaca Paviani (2014, p. 36): “[...] fazer e aprender ciência hoje requer novos espaços e modalidades de aprendizagem, e isso implica uma revisão do conceito tradicional de disciplina". 
Figura 1 - Cartografia da Implementação da Estratégia 12.7 do PNE

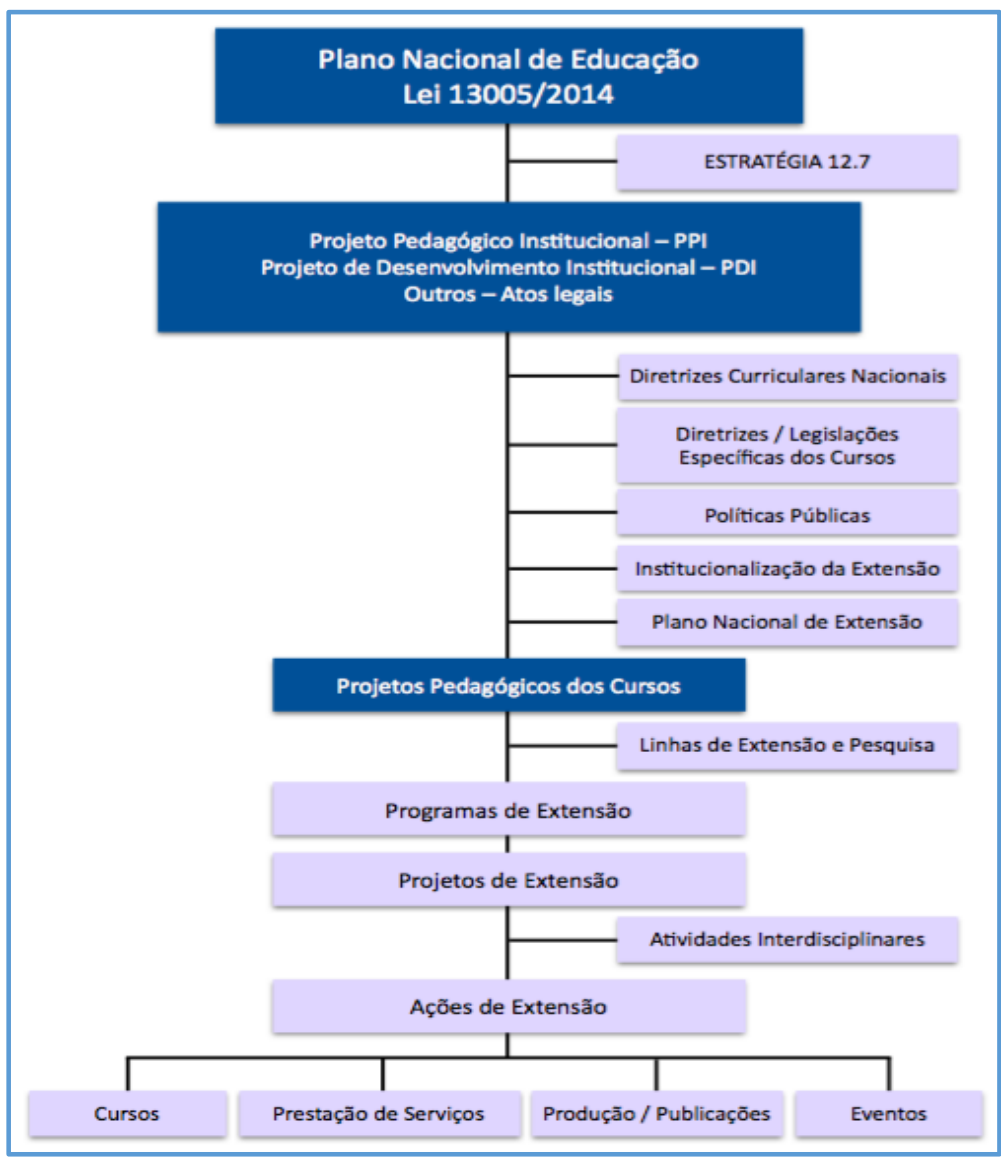

Fonte: Elaborada pela autora.

Contudo, se uma primeira leitura da estratégia 12.7 do PNE 20142024 mobiliza e inspira todos os que defendem uma concepção de educação superior orientada para além da formação profissional, descortinando um universo de possibilidades, desnuda entraves e dificuldades a serem enfrentados em sua implementação, conforme elencam Imperatore e Pedde (2015, n.p.): 
A mercadorização da educação;

$\mathrm{O}$ academicismo e o autoritarismo da universidade despreparada para o diálogo de saberes com a sociedade;

A departamentalização da universidade que implica a fragmentação do conhecimento, na irreconciabilidade de ensino, pesquisa, extensão e gestão, tendo como consequências o encarceramento do conhecimento na sala de aula/ensino, a hierarquização do conhecimento, a histórica posição subalterna da Extensão, a subordinação das funções acadêmicas à gestão;

A imprecisão teórico-conceitual e metodológica, o conflito identitário da Extensão latente e presente nos documentos institucionais e na legislação, sua insuficiente sistematização e incipiente avaliação, que redundam na proposição de meros e simples arranjos, inserções de ações desarticuladas na "grade curricular";

A armadilha do currículo, da disciplinaridade, da compartimentalização que ameaçam a lógica extensionista, seu sentido epistemológico, sua essência crítica e interdisciplinar;

A deficiente formação docente em Extensão, a desvalorização do fazer extensionista na carreira, a remuneração e o currículo docente;

A gestão empresarial da Extensão, alheia às diretrizes pedagógico-acadêmicas, com foco mercantil;

Os potenciais impactos, orçamentário e temporal, da flexibilização curricular, aliados ao insuficiente financiamento público de programas e projetos de Extensão.

Some-se aos entraves e dificuldades citados a "babelização" das discussões sobre a estratégia 12.7, por meio de diferentes fóruns que não dialogam entre si (Fórum de Graduação, Fórum de Pesquisa e PósGraduação, Fóruns de Extensão), por vezes não dialogam com a sociedade e, no caso específico da extensão, sequer conseguem integrar instituições 
públicas, comunitárias e privadas. A discussão “intramuros” também carece de intensificação com vistas a mobilizar a comunidade acadêmica acerca do desafio e delineamento de trajetórias possíveis (e viáveis) para a efetiva "extensionalização do currículo". Contudo, ressaltam Imperatore e Pedde (2015, n.p.):

No patamar das boas intenções, não podemos ser cúmplices da subversão (e submissão) da Extensão a partir de reducionismos, formalismos inadequados, soluções simplistas e superficiais. Para além de novos arranjos didático-metodológicos, a discussão é epistemológica, com vistas à construção de projetos sistêmicos, coesos e coerentes que deem conta das novas linguagens, imagens, lógicas, conceitos, experiências intersubjetivas, habilidades e competências cognitivas, daí concluir-se que o ponto de partida para a implementação dos $10 \%$ de Programas e Projetos integrados ao currículo não é a discussão de uma nova segmentação do currículo mantida a segregação de disciplinas, as unidades administrativas, as diretrizes político-institucionais, mas a retomada da reflexão acerca dos diferentes saberes, sob a perspectiva da interdisciplinaridade.

\section{CONSIDERAÇÕES FINAIS}

A transição paradigmática do ensino superior brasileiro ante a estratégia 12.7, do Plano Nacional de Educação (PNE), eleva a extensão ao status de função acadêmica integrada ao currículo, enquanto elo universidade-sociedade orientador da pesquisa, do ensino e da gestão. Mais do que uma mera combinação quantitativa, a mudança proposta é epistemológica, propondo a efetiva indissociabilidade da extensão, pesquisa e ensino, tendo por trajeto um currículo marcado pela deposição da compartimenta- 
lização disciplinar, da sala de aula como único ethos de aprendizagem, da promoção da (re)territorialização da universidade. Mais do que um projeto genérico de "curricularização", é preciso (re)pensar a singularidade de cada projeto pedagógico em resposta aos questionamentos: Que universidade queremos? Que profissionais formaremos? Como a extensão contribuirá para a efetivação da política e das diretrizes institucionais?

Ao defender o movimento de aproximação da universidade com a sociedade na perspectiva de enfrentamento de pautas reais, ressignifica-se o currículo de forma a evitarmos a mera inserção de "apêndices" que tratem de forma desconexa a formação acadêmica e cidadã. Proponho reflexões fundamentadas na práxis extensionista, na escuta dos protagonistas dessas ações (docentes, discentes e comunidades), na institucionalização do fazer extensionista, à luz da política nacional vigente, na sua sistematização em sistemas informacionais (que deem conta do registro, controle/ monitoramento, avaliação e evidenciação). Eis os pontos de partida, consciente de que há um longo caminho a percorrer.

\section{REFERÊNCIAS}

BOTOMÉ, S. P. Pesquisa alienada e ensino alienante: o equívoco da extensão universitária. Petrópolis: Editora Vozes, 1996.

BRASIL. Lei no 13.005, de 25 de junho de 2014. Aprova o Plano Nacional de Educação - PNE e dá outras providências. Diário Oficial [da] República Federativa do Brasil. Brasília, DF, 26 de junho de 2014a [Edição Extra]. Disponível em: <http://www.planalto.gov.br/ccivil_03/_Ato20112014/2014/Lei/L13005.htm>. Acesso em: 29 jun. 2014.

BRASIL. Ministério da Educação. Sinopses estatísticas da educação superior: graduação 2013. Publicado em 2013. Disponível em: <http://inep.gov. br/sinopses-estatisticas-da-educacao-superior $>$. Acesso em: $1^{\circ}$ ago. 2015. 
Edital PROEXT 2014. Publicado em 2014b. Disponível em: $<$ http://portal.mec.gov.br/index.php?option=com_docman\&view=download\&alias=15149-edital-proext-2015\&category_slug=fevereiro-2014\&Itemid=30192>. Acesso em: 21 jul. 2015.

DEMO, P. Lugar da Extensão. In: FARIA, D. S. de (Org.). Construção conceitual da extensão universitária na América Latina. Brasília: UNB, 2001.

FARIA, D. S. de (Org.). Construção conceitual da extensão universitária na América Latina. Brasília: UNB, 2001.

FÓRUM DE PRÓ-REITORES DE EXTENSÃO DAS INSTITUIÇÕES PÚBLICAS DE EDUCAÇÃO SUPERIOR BRASILEIRAS - FORPROEX. Política Nacional de Extensão Universitária. Manaus: FORPROEX, 2012. Disponível em: <http://www.renex.org.br/documentos/2012-07-13-Politica-Nacional-de-Extensao.pdf $>$. Acesso em: 14 dez. 2014.

FREIRE, P. Extensão ou Comunicação. 13. ed. São Paulo: Paz e Terra, 2006a.

FREIRE, P. Pedagogia da Autonomia: saberes necessários à pratica educativa. In: SERRANO, R. M. S. M. Conceitos de extensão universitária: um diálogo com Paulo Freire. 34. ed. São Paulo: Paz e Terra, 2006 b.

GRAMSCI, A. Os intelectuais e a organização da Cultura. 71. ed. Rio de Janeiro: Civilização Brasileira, 1989.

IMPERATORE, S. L. B.; PEDDE, V. "Curricularização" da extensão universitária no Brasil: questões estruturais e conjunturais de uma política pública. In: CONGRESSO LATINO-AMERICANO DE EXTENSÃO UNIVERSITÁRIA, 3., 2015, Cuba. Anais... Cuba: ULEU/Ministério da Educação Superior da República de Cuba, 2015. Disponível em: <http:// www.congresoextension.mes.gob.cu/documentos/CLEU\%20(VF).pdf $>$. Acesso em: 12 jul. 2015.

JEZINE, E. As práticas curriculares e a extensão universitária. In: CONGRESSO BRASILEIRO DE EXTENSÃO UNIVERSITÁRIA, 2., 2004, 
Belo Horizonte. Anais... Belo Horizonte: UFMG, 2004. Disponível em: <https://www.ufmg.br/congrext/Gestao/Gestao12.pdf>. Acesso em: 14 dez. 2014.

MENÉNDEZ, G. et al. Integración docência y extensión: outra forma de enseñar y de aprender. Santa Fé: Universidad Nacional del Litoral, 2013.

MORIN, E. O método 3: conhecimento do conhecimento. Trad. Juremir Machado da Silva. 4. ed. Porto Alegre: Sulina, 2012.

PAVIANI, J. Interdisciplinaridade: conceitos e distinções. 3. ed. Caxias do Sul: Educs, 2014.

SANTOS, B. S. A crítica da razão indolente: contra o desperdício da experiência. 8. ed. São Paulo: Cortez, 2011.

SANTOS, B. S. S. Pela mão de Alice: o social e o político na pós-modernidade. 14. ed. São Paulo: Cortez, 2013.

SILVA, M. G. M. Extensão universitária no sentido do ensino e da pesquisa. In: FARIA, D. S. de (Org.). Construção conceitual da extensão universitária na América Latina. Brasília: UNB, 2001.

SOUSA, A. L. L. A história da extensão universitária. 2. ed. Campinas: Editora Alínea, 2010.

TAVARES, M. das G. M. Os Múltiplos Conceitos de Extensão. In: FARIA, D. S. de (Org.). Construção Conceitual da Extensão Universitária na América Latina. Brasília: UNB, 2001. 